\title{
Giampaolo Proni*
}

\section{Umberto Eco and Charles Peirce: A slow and respectful convergence}

DOI 10.1515/sem-2015-0021

\begin{abstract}
The aim of the essay is to link Eco's theory of the Encyclopedia as regulative hypothesis with his theory of interpretation, by evidencing the intrinsic dynamic character of the encyclopedic model. Eco adopts Peirce's view of semiosis as a flow of interpretants, but the notion of semantic model is not to be found in the work of the American. Eco is thus attracted by the challenge of combining the process-based model of interpretation and the formal model of semantic system. The attempt meets with some difficulties due to the difference between the two approaches. Yet, it is argued that this attempt opens a fascinating landscape to future research.
\end{abstract}

Keywords: Eco, encyclopedia, Peirce, semiosis, interpretants, semantic model

\section{Introduction}

Umberto Eco took many of his semiotic concepts from Peirce, beginning in the 1960s and increasing his Peircean inspiration over the course of the years. At first glance, the two seem to have little in common.

While Peirce dedicated his life "To erect a philosophical edifice that shall outlast the vicissitudes of time" (CP 1.1), where semiotics is placed in an organized classification of science (see Proni 1992), Eco never wanted to give his theory of the sign an explicit philosophical foundation. This does not mean Eco has no implicit philosophy. And he appears to be more inclined towards nominalism than realism. At the same time, Eco made his intellectual debut taking a stand against idealistic aesthetics, whose main Italian representative was Benedetto Croce, the dominant figure in Italian philosophy in the first decades of twentieth century (Eco 1962; Proni 1988, Proni 1998). Since Peirce professed on several occasions to be

*Corresponding author: Giampaolo Proni, Department for Life Quality Studies, Bologna University, C.so D’Augusto, 237 Rimini 47921, Italy, E-mail: giampaolo.proni@unibo.it 
a realist (a scholastic or Scotist realist, to be precise) ${ }^{1}$ and an idealist (close to Schelling's position; $C P 4.453,5.102$ ), it seems that the two belong to opposite philosophical fields.

It would require too many pages to explain why, over three decades, Eco has taken so much from Peirce but not his philosophical approach. This choice, however, left Eco with a weak foundation for his semiotics, and he became progressively aware of this lack, particularly with regard to the problem of semiosis in perception.

In the 1960s Eco can still be defined as a structuralist, though he is very clear in denying an immanent character to any structure (see Eco 1968a). Then he progressively comes closer and closer to Peirce's positions, trying at the same time to maintain two points: the conventional nature of signs and the central role of codes. The first implies the second, and the role of codes is later reduced to a particular case in the more general theory of the interpretant (Eco 1984a).

Eventually, in Kant e l'ornitorinco (1997) [Kant and the Platypus, 1999], Eco showed he had found in Peirce an approach to the foundation of semiotics he might embrace without surrendering to metaphysical bents, namely, phenomenology. In fact, Eco had been intellectually raised in an existentialist and phenomenological environment, and it was natural for him to adopt such a stance. Nonetheless, even now he still does not take an explicit philosophical position.

In Kant and the Platypus, then, the nature of the sign remains conventional, but a kind of "basic semiosis" is introduced in order to have a starting point for interpretation or decoding. Basic semiosis is, Eco writes "a message without a code" (1999a: 383, note 35). Thus implying that there are non-conventional signs.

Therefore Eco, eventually, though in an indirect way, adopts Peirce's phenomenological view, but he still refuses to go beyond the empirical, ordinary sensorial representations that he calls "alfa mode" (Eco 1999a: 383). To be without a code a message must have no division between content and expression, since the code is the relation between them. In Peirce this happens only with Qualities of Feeling, but they have a particular mode of being or ontological status: that of Possibility or Firstness. And Firstness appears (we cannot say “exists” since Qualities of Feeling “seem” but don't “exist”) before the distinction between the inner and the outer world, the Self and Not Self, arises in consciousness (CP 1.354-1.368, 5.41-5.56). Eco respects the division between

1 Anybody may happen to opine that "the" is a real English word; but that will not constitute him a realist. But if he thinks that, whether the word "hard" itself be real or not, the property, the character, the predicate, hardness, is not invented by men, as the word is, but is really and truly in the hard things and is one in them all, as a description of habit, disposition, or behavior, then he is a realist. (CP 1:27; see, for example, $C P$ 4.1, 4.50; 5.470; 6.612, 6.613) 
semiotics and philosophy: he does not want to take ontological positions. In 1999, however, his approach to Peirce's theory is almost complete. With the acceptance of basic semiosis, the notion of sign is founded on a non-conventional basis, and the central role of code is abandoned in favor of an interpretive explanation.

Thus, the relation between Eco and Peirce can be outlined as a progressive convergence. Let us now try to see in more detail the history of this slow but steady discovery and acknowledgment.

\section{1968: the inquiry on codes}

Umberto Eco's work on semiotics began within the debate on structuralism, which was vibrant in the European cultural landscape of the 1960s. His contribution appeared in the book, La stuttura assente (1968) ${ }^{2}$ [The Absent Structure] with the subtitle Introduzione alla ricerca semiologica [Introduction to semiotic research]. ${ }^{3}$ Eco had encountered French structuralism, Roman Jakobson and Russian formalism some years before. The book that launched him onto the Italian intellectual scene was Opera aperta (1962) [The Open Work], which focused mainly on the aesthetics of interpretation with its starting point in the work of Luigi Pareyson, the supervisor of his dissertation. Already at this time, the central role of interpretation in aesthetics and semiotics was clear to Eco and when he discovered Peirce (through Jakobson, Morris, and Ogden and Richards), he found a confirmation and, moreover, a semiotic treatment of the interpretive process that was a more logically and philosophically correct description.

In La struttura assente (1968a) [The Absent Structure], Eco comes up with an original synthesis between the semiology of French origin and Peirce's and Morris' semiotics. The structuralist influence is still strong, though moderated by a pragmatic stance (Eco 1968a: 360 and Section D), and Peirce's theory of the interpretant is explicitly presented (1968a: 35-36). The theory is described only in brief, yet Eco clearly sees in the Peircean notion of interpretant a productive

2 See the Introduction in this volume on the problem of the various translations and editions of Eco's works in English and in Italian.

3 Semiology and Semiotics, and the adjectives semiologic and semiotic, are both used in Italian as semiologico and semiotico. Originally, Semiology referred to the theory as it was developed by De Saussure and his followers, mainly French, while Semiotics was used by scholars closer to Peirce's approach, initially American or writing in English. Eco began his work using the first term then passed to the second, and this passage corresponds to his gradual approach to Peirce's theory. Today the term semiology is out of use in both schools. 
possibility for his semiotics. Since, as Eco writes, the interpretant is, in Peirce's view, "another representation that refers to the same object"4 (1968a: 36, my translation), then the only way to establish the interpretant of a sign is by means of another sign, and so on, in a repetitive series called "unlimited semiosis," a key concept developed by the American philosopher. Interpretation will thus be capable of self-reflection, "language would then be a system that clarifies itself, by means of successive systems of conventions that explain each other" (1968a: 36). In 1968, Eco is still reluctant to admit that the theory of interpretation can remove the need for a metalanguage in order to talk about meaning; he just notices that this way the code explains itself and that "since a language that talks about language is a metalanguage, then semiology brings about a hierarchy of metalanguages and nothing else" (1968a: 37).

At this stage Eco's semiotics pivots on the notion of code. In the analysis of cinema, advertising, architecture, the keys are always the visual codes that allow one to grab the more or less hidden meanings. However, in codes, Eco is less interested in the structure of codes than in the continuous change produced by artistic and communicative practices (1968a: 97).

\section{1975: the supremacy of interpretation}

La struttura assente [The Absent Structure] marks the beginning of a semiotic inquiry that continues to develop with Le forme del contenuto (1971) [The Form of the Content] e Il segno (1973) [The Sign], assuming a definitive form in Trattato di semiotica generale (1975a) [A Theory of Semiotics, 1976a], in which Peirce's theory of interpretation plays a fundamental role. A whole chapter is dedicated to its explanation (1976a: Ch. 2.7).

Eco adopts, with some changes, Peirce's definition of sign, ${ }^{5}$ "I propose to define as a sign everything that, on the grounds of a previously established

4 Original Italian text from La Struttura Assente, “quella di vedere l'interpretante come un'altra rappresentazione che si riferisce al medesimo oggetto" (1968a: 36.); "il linguaggio sarebbe allora un sistema che si chiarifica da sé, per successivi sistemi di convenzioni che si spiegano a vicenda" (1968a: 36); "poiché un linguaggio che parla sul linguaggio è un metalinguaggio, la semiologia ad altro non porterebbe che a una gerarchia di metalinguaggi" (1968a: 37).

5 "A Sign, or Representamen, is a First which stands in such a genuine triadic relation to a Second, called its Object, as to be capable of determining a Third, called its Interpretant, to assume the same triadic relation to its Object in which it stands itself to the same Object" ( $C P$ 2.274). For the definitions of sign see Bonfantini (1980: xxx); Proni (1990: 232-233); and Speculative Grammar in the second volume of Collected Papers. Peirce gave several definitions of sign, some of them are incomplete, but they are all coherent. 
convention, can be taken as something standing for something else" (1976a: 16). The change in Peirce's theory seems to be a minor detail, yet it carries much weight. While, in Peirce, convention is only one of the three relations a sign can have to its object ("what it stands for"), Eco defines the sign function, following Saussure, only as a conventional relation. This allows him to preserve the central role of code, "The process of signification takes place only when a code exists." ${ }^{6}$ The notion of code, however, becomes in Eco something very different from Saussure and Hjelmslev.

First, Eco looks for a more specific definition of code. In this search, he criticizes, one by one, the different semantic models for their naturalistic or ontological biases (1976a: 126), and ends with the Global Semantic Universe or Model "Q" (1976a: 121), a "working hypothesis" not entirely representable and based on "a process of unlimited semiosis" (1976a: 122). In fact, since the code is not an a priori entity but an explicative hypothesis, then it is the product of semiotic activity and not its condition, and because such activity is based on interpretation, the code is just the trace of all the interpretive acts of a given culture, namely, the perpetual flow of semiosis.

Interpretive activity, though, does not end once a code is produced. A successful model must also account for its use and continuous change. Interpretation has the logical form of inference. The theory of inference or argument is a keystone not only of Peirce's semiotics (or logic, Peirce, following Locke, identified logic with semiotics; see $C P$ 2.227) but for his whole philosophical system. In Peirce, the Universe itself is a sort of gigantic argument unrolling itself in infinite evolution towards final logical perfection. Semiotically speaking, inference, according to Peirce, is a kind of sign (CP 2.252). Inference plays a role in establishing conventions (Eco 1975a: 29) and in interpreting uncodified expressions. Thus Eco presents the Peircean notion of abduction, the form of reasoning introduced in logic by Peirce (Eco 1975a: 185). ${ }^{7}$ The inferential nature of semiosis will become from now on more and more clear in Eco's theory: interpretation is always an inferential act, what changes is only the degree of automatism and the certainty of conclusion.

Interpretation thus becomes a more general concept than code, because it does not explain only the decoding of expressions but also the production

6 In Trattato di semiotica generale Eco writes, "Il processo di significazione si verifica solo quando esiste un codice" (1975a: 19). In the American edition the text is different: "This process is made possible by the existence of a code" (1976a: 8): the code allows for the process but is not a necessary condition ("only when") as in the Italian version.

7 On abduction see Proni (1981; 1983); Bonfantini (1987); Eco and Sebeok (1984). 
of sign-functions (Eco 1975a: 185-187). Eco is careful, as Peirce himself was, to leave no room for mentalism, and he quotes one of Peirce's definitions of the interpretant as "that which the sign produces in the quasi-mind which is the interpreter; but it can also be conceived as the definition of the representamen (and therefore its intension)" (Eco 1976a: 68). Eco then defines the interpretant as "another representation which is referred to the same 'object'." (1976a: 68). Such representations can be of five different kinds: equivalent sign-vehicles; indexes directed to an occurrence or quantifiers; definitions; emotive associations with connotative value; translations into another language (Eco 1976a: 70). Now unlimited semiosis is seen in a more assertive way as an alternative to metalanguage: "Semiosis explains itself by itself ... this continual circularity is the normal condition of signification and even allows communication to use signs in order to mention things" (Eco 1976a: 71).

Yet, although Eco admits that the notion of interpretant is more comprehensive, he does not abandon the idea of mixing it with that of code. For this reason he builds a restricted definition of interpretant, capable of functioning within the framework of the code theory, limited to three semantic categories: a) synonymy; b) componential representation of a sememe; c) seme or semantic component (Eco 1976a: 72).

In $A$ Theory of Semiotics interpretation also plays a fundamental role in the theory of mentioning or referring. Eco does not oppose an inferential conception of signification to an intuitive notion of perception but sees the "problem of perception as interpretation of sensory disconnected data which are organized through a complex transactional process by a cognitive hypothesis based on previous experience" (1976a: 165). Perception is thus a semiosic process, a representation, a sign, and concepts are also signs (CP 5.264-317). Eco refers not only to Peirce but also to the psychology of perception of Jean Piaget, to the nominalistic British tradition, and to Edmund Husserl. "The object," Eco writes, "is not necessarily a thing or a state of the world: it is rather a rule, a law, a prescription” (1979a: 29, my translation). ${ }^{8}$ However, as with any constructive theory of perception, the problem is only moved, not solved. There must always be some first elements of knowledge that are not produced by the subject, otherwise there is no knowledge of the external world. And how do these elements account for the external world? These questions will only find an answer in Eco several years from now.

8 Original text from Lector in fabula, "L'oggetto non è necessariamente una cosa o uno stato del mondo: è piuttosto una regola, una legge, una prescrizione” (1979a: 29). 


\section{1979: towards a pragmatics of texts}

In $A$ Theory of Semiotics Eco adopted Peirce's theory of interpretation, in Lector in fabula (1979a) ${ }^{9}$ he extended the theory to textual semiotics. Eco starts from Peirce's division between Dynamical and Immediate Object or Ground. ${ }^{10}$ The Dynamical Object is the "really efficient but not immediately present Object" ( $C P$ 8.343), that to which the Sign directs, while the Immediate Object is "the Object as the Sign represents it" (CP 8.343). Interpretant and Immediate Object or Ground are, in Peirce, synonyms of meaning (although with some differences). One of the peculiar features of Peirce's semiotics is that meaning is not a central concept. The term itself is used in its common sense and does not appear in the definitions of representation or Sign. Of course, Peirce has a theory of meaning, in the sense in which linguistics and semiotics have considered it in the twentieth century, but it has to be framed in the triadic model, and not in the expressioncontent (or biplanar) model. In extreme synthesis, we might say that each of the three elements of Representation possesses some properties of meaning. Immediate Object is the significant part of the Sign (being the Representamen the mere sign-vehicle), that is, the portion of the thing or event that carries the information (see Eco 1979b: 183).

For example, in a weathercock, the Immediate Object is the direction it assumes, while its color, smell, and other features have no semiotic function. This is only a part of its meaning. The Interpretant takes into account the Immediate Object and assumes that it stands for its Dynamical Object: "This weathercock shows that the wind blows form the North.” Thus, the interpretant means here and now in its pragmatic signification, that is, the full meaning, which includes context and its circumstances. The Dynamical Object is that which puts the whole process in motion, standing behind the scenes, unreachable in its completeness (as the Ding an Sich in Kant) but effective in its empirical existence. In interpretation it is that part of meaning that has to do with the infinite approach to the referent, its "unveiling." To stick to our example, the rotation of the weathercock can convey another trait of its Object (the wind), namely, that it is inconstant.

9 Lector in fabula (Eco 1979a) is a 218 page book that has the same title as a sixty-page essay included in The Role of the Reader (Eco 1979b), which is clearly a synthesis of the former.

10 Peirce uses upper case for the semiotic terms or concepts when he gives their definitions and is speaking about them in a general way, but he is not always consistent (we must consider that many of Peirce's texts are manuscripts). I will use capitals when referring to those terms as Peircean concepts, and lower case when using them as shared semiotic concepts. 
If we look at the other side of interpretation, namely, to sign production, the Object must be in the background when we progressively add to the sign more traits of the Referent. For example, I may add to the weathercock a rotating wheel to measure, besides direction, the speed of wind.

Another idea of Peirce that was taken up by Eco is that a term (or rheme) is a potential proposition, and a proposition (or dicisign) a potential argument. This allows him to say that "the meaning of a sign inchoatively contains all the texts within which that sign can be inserted" (1979b: 184). From this point he develops one of the central theses of the book, " $a$ sememe is in itself an inchoative text, whereas a text is an expanded sememe" (1979b: 175). This conclusion represents an extension with respect to Peirce. While Peirce limited the expandability of term and proposition to their logical consequences, Eco added the possibility of expansion on the basis of discoursive implications, produced by interpretations sedimented in the Encyclopedia (or Global Semantic System or Model Q). In doing this, Eco corrects his own definition of the interpretant in a less "lexicalist" direction, "we must not forget that, for Peirce, not only a word or an image are signs, but also a proposition or a whole book"11 (1979a: 35, my translation).

In Lector in fabula Eco raises, for the first time, the problem of the limits of interpretation, which will assume more and more relevance in his later research. The question, synthetically put, is that since the interpretative process takes the form of unlimited semiosis, "This infinite series could, however, make the semantic encyclopedia unattainable and the work of semantic analysis continuously baffled by its own need of completedness" (1979b: 189). It is thus necessary to somehow contain the interpretive fugue. According to Peirce, the flow of interpretation originated by a sign takes a rest (it does not die, because it can always be revived) with the formation of conscious habits, namely, norms for action, called Final Interpretants (see Peirce CP 5.11-13; 5.464-494). This is the core concept of pragmatism, defined by Peirce as "a method of ascertaining the meanings of hard words and of abstract concepts" (CP 5.464) by developing their conceivable consequences.

Eco initially acknowledges two limits to interpretation. The first is the universe of discourse itself. In ordinary discourse, in fact, we do not consider an infinite number of semantic implications (though it would be theoretically possible) but we limit the encyclopedic representation in such a way as to be both logically acceptable and viable (Eco 1979a, Eco 1979b: 88). The second is Peirce's pragmatic limit. Eco poses the problem, which never troubled Peirce,

11 Original text from Lector in Fabula: "non bisogna dimenticare che per Peirce non è segno solamente una parola o una immagine, ma una proposizione e addirittura un intero libro" (1979a: 35). 
about which habit a literary text might bring about, considering that it is bound to be different to that which the interpretation of a chemical definition, consisting of a series of operative instructions, requires. ${ }^{12}$ One hypothesis is that some literary texts produce "messages," in the sense of moral syntheses. Eco's example is Le rouge et le noir by Stendhal, which "prescribes what one must do in order to acquire the practice of acting and modifying the world"13 (1979a: 49, my translation). There are obviously more possibilities. The final interpretant of an aesthetic text can be the request for further reading moved by the mere pleasure of fruition, a change in introspective attitude, the choice of correcting one's behavior in a sometimes radical manner, and so on. Certainly here individual competences and local encyclopedias also come into play.

Extending pragmatism to cover the case of literary texts raises another question, namely, the testing of interpretations. In fact, according to Peirce, habits produced by interpretation are selected by interaction with the environment, following the theory of evolution. Yet, this happens only with habits that imply such a selective interaction "outside of these it is probably of more advantage to the animal to have his mind filled with pleasing and encouraging visions, independently of their truth; and thus, upon unpractical subjects, natural selection might occasion a fallacious tendency of thought" (CP 5.366). The pragmatic approach to text does not necessarily produce an intellectual aesthetics. Acquiring pleasant sensations can be as useful as logical correctness of thought, and that is without considering that a hedonistic effect is not completely devoid of any practical value.

\section{1984: Peirce in the labyrinth}

In Semiotica e filosofia del linguaggio (1984a) [Semiotics and the Philosophy of Language, 1984b] ${ }^{14}$ Eco adds to the theory of interpretation by improving the

12 See the famous "pragmatic" definition of Lithium in CP 2.330, also quoted by Eco (1979a: 37, 1979b: 187).

13 Original text from Lector in Fabula, "prescrive cosa bisogna fare per acquisire abitudini alla azione e alla modificazione del mondo" (1979a: 49).

14 In 1984 Eco published in English Semiotics and the Philosophy of Language (1984b). The book contains seven essays: "Signs," "Dictionary versus Encyclopedia," "Metaphor," "Symbol," "Code," "Isotopy," and "Mirrors". The last two are not included in the Italian edition of Semiotica e filosofia del linguaggio (1984a). And, of particular relevance to us here, the essay "Encyclopedia" is different from the Italian version "Dizionario versus Enciclopedia," it is shorter and it lacks the whole first part on "meaning," which is relevant to the discussion in this paper. 
notion of encyclopedia, "the only model capable of accounting for the complexity of semiosis, both on the theoretical level and as a regulative hypothesis on actual processes of interpretation" (1984a: 255, my translation). ${ }^{15}$ Eco explicitly criticizes the notion of code.

It is thought that the model of encyclopedia is the most important of Eco's contributions to semiotics. It has been said that the theory is not complete and that it lacks the rigor of other semantic theories. ${ }^{16}$ I believe that this contributes to its value, and is not a flaw. Theories that open the way to further inquiry can be as good as those which organize the data in a reasoned and closed order. The rigorous debate about the best formal semantic model, so lively until the 1980s, has silently turned to more practical, almost humble research, which is channeled into computer science and AI applications. Neurological research, on the other hand, has shown that we are still far from mapping the interpretive processes in the brain at cellular level. Thus, instead of looking for what meaning "really" is in humans, AI researchers try to associate input to output expressions in the best way they can, often relying on learning algorithms, like neural networks, that build rules from the actual use of language or other systems of signs. Research into human interpretation is therefore, once again distant from formal models of meaning.

The encyclopedic model still provides two important positive contributions. First, it gives a good description of cultural influences in text comprehension, and this answers to a need that the globalized world expresses with increasing urgency. Immanent theories of meaning, as in generative semiotics and all biplanar or code-based approaches, provide no explanation of cultural divergences of interpretation if not that the right code has not been used. The question becomes then: "What is the right code?," but such a question does not necessarily have an answer. Just think of texts like the Bible or the Koran.

And second, the encyclopedia puts together processual and systematic approaches. The task is still in progress, but there is no doubt that this is the right solution. It is widely accepted that interpretation can (and must) be seen at the same time as a system or structure, and as a process or development. Yet, to build a model which is both dynamic and systematic is not an easy job, and surely there is a lot of further research to be done. ${ }^{17}$ I will expand a little more on

15 Original text from Semiotica e filosfia del linguaggio, "l'unico modello capace di render ragione, sia sul piano teorico, sia come ipotesi regolativa per processi concreti di interpretazione, della complessità della semiosi” (1984a: 255).

16 For a discussion on Eco's Encyclopedia see Violi (1998).

17 In this direction the theory of Semiosphere, developed by Jurij Lotman (1990), constitutes a more articulate approach to a social theory of interpretation (or meaning). Lotman's theory is a semiotic of culture rather than a study of meaning, but this is what encyclopedia (and any theory of meaning) eventually must be. 
this point, and I will explain where Eco took his inspiration from, and how he described his model.

Encyclopedia is the model for an interpretant-based semantics. In this approach interpretation definitely leaves behind any lexicalist restriction, “... the sign is always what opens myself to something other. There is no interpretant that, in equating the sign it interprets, does not expand, even slightly, the sign's borders" (1984a: 52, my translation). ${ }^{18}$

The encyclopedic model represents a goal in Eco's research. It is the framework of semiotic habits that the infinite colony of interpreters deposit as the result of its continuous acts of signification, like the skeleton created by a colony of coral. It constitutes the point of real synthesis between the dynamic conception of Peirce and the synchronic structuralist view, a true synthesis because it is a new conceptual object in which there are no visible stitches but only various references to the history of philosophy. The aim is to build a non-rigid model of the semiotic competence of individuals, groups and cultures. The model is composed both of empirical data and formal principles, since it presumes that

1) properties are not semantic primitives but interpretants, that is, different expressions that in their turn may become subjects of a further representation; 2) the contexts and circumstances are not infinite but are those which, statistically, according to a hypothesis of standard competence (or with regard to the competence required by a certain co-text), are believed to be part of the encyclopedic competence of the sender or of the receiver. (Eco 1984a: 119)

The encyclopedic model provides a further limit to interpretation:

A textual semiotics also studies the rules by which the interpreter of a text, on the basis of "signals" contained in the text (or even on the basis of previous knowledge) decides which format of encyclopedic competence is required to deal with that text. In this way also the discriminant between interpretation of a text and the indiscriminate use of it can be established. (1984a: 110, my translation) ${ }^{19}$

18 Original text from Semiotica e la filosofia del linguaggio, “... il segno è sempre ciò che mi apre a qualcosa d'altro. Non c'è interpretante che, nell'adeguare il segno che interpreta, non ne sposti sia pure di poco i confini” (1984a: 52).

19 Original text from Semiotica e la filosofia del linguaggio:

1) le proprietà non siano primitivi semantici ma interpretanti, e cioè altre espressioni che a loro volta possono diventare soggetto di una successiva rappresentazione; 2) i contesti e le circostanze registrati non siano infiniti ma siano quelli che statisticamente, secondo una ipotesi di competenza media (o in riferimento alla competenza richiesta da un certo co-testo) si ritengono parte della competenza enciclopedica dell'emittente o del destinatario. (Eco 1984a: 119) 
We may call this criterion the "criterion of implicit competence," which is the same as Eco's notion of Model Reader (1979b: 7), seen as the set of instructions that actualize the text in the most coherent way.

\section{Rhizome and encyclopedia}

Eco compares encyclopedia to the model described by Deleuze and Guattari (1976), called rhizome. Deleuze and Guattari do not explain in their text what a rhizome is. They talk about a "system," "the book" in the general sense. They seem to privilege the pure formal character, the capacity of the rhizome to be a general model, but with no particular object. A model of discourse, a model of text, a model of the world.

As we have seen, in A Theory of Semiotics (1976a) the encyclopedia was a semantic representation that corresponded to the componential model. In Semiotics and the Philosophy of Language (1984a), Eco seems to use the term encyclopedia to refer to some intensional semantic models, similar to the Model $\mathrm{Q}$, and actually the two texts present many similarities. Above all, the encyclopedic model is said to permit the description of the process of unlimited semiosis and linguistic creativity.

However, in Semiotics and the Philosophy of Language the role of encyclopedia is extended, as we will see, to represent the whole "universe of semiosis" in its form, its contents and its functioning. Deleuze and Guattari's purpose was slightly different from Eco's. Nevertheless, Eco in his work follows the French authors. Both texts refer to Rosenstiehl and Petitot's mathematical study of labyrinths (Rosenstiehl and Petitot 1974; Rosenstiehl 1971, Rosenstiehl 1979, Rosenstiehl 1980; Petitot 1977), but the original rhizomatic theory derives from the political criticism of psychoanalysis and linguistics. ${ }^{20}$ Deleuze and Guattari explicitly attack the rigid and incomplete models of those disciplines, while Eco keeps his theory separate from ideological discussion. Furthermore, by calling his model "encyclopedia," Eco calls into play an explicit parallel with the Encyclopédie and the system of culture as conceived by the Enlightenment.

Una semiotica testuale studia anche le regole in base alle quali l'interprete di un testo, sulla base di "segnali" contenuti in quel testo (e magari sulla base di una conoscenza precedente) decide quale sia il formato della competenza enciclopedica necessaria ad affrontare quel testo. Il che stabilisce anche la discriminante fra interpretazione di un testo e uso indiscriminato dello stesso. (Eco 1984a: 110)

20 See Deleuze and Guattari $(1972,1987)$; the latter, called A Thousand Plateaus, is a collection of Deleuze and Guattari's papers in English, which also includes "Rhizome." 
Yet, Eco, too, strongly criticizes the traditional semantic models, reducing them to particular cases of a more general theory.

Deleuze and Guattari and Eco divided their texts in numbered points, trying to make a list of the properties of their models. I will follow this scheme.

\subsection{Connectibility}

The first point is called by Deleuze and Guattari "Principe de connexion" [principle of connection], and states that "any point of a rhizome can be connected to anything other, and must be” (1987: 7). Eco paraphrases this statement and comments on Deleuze and Guattari's text (Eco 1984a: 81). The theory of interpretation had already adopted such an explanation of meaning. Eco puts together Peirce's theory of the fugue of interpretants with Deleuze and Guattari's concept of rhizomatic net and writes that the encyclopedia "is structured according to a network of interpretants" (Eco 1984a: 83). ${ }^{21}$

This definition proves to be better than that of a static net because it adds the dynamic property of the continuous flux of interpretants to the synchronic image of a set of interconnected points. At the same time, the net adds a multidimensional character to the unidirectional development of interpretants, which, incidentally, was not the way Peirce intended it. Peirce had already observed that scientific reasoning is not a chain, in which the whole is as weak as the single part (if one link breaks the chain is broken) but a cable, made of many wires, so that if one of them is interrupted the cable still holds (see CP 5.3).

\subsection{Heterogeneity}

The second point listed by Deleuze and Guattari is the principle of heterogeneity, "A rhizome ceaselessly establishes connections between semiotic chains, organizations of power, and circumstances relative to the arts, sciences, and social struggles. A semiotic chain is like a tuber agglomerating very diverse acts, not only linguistic, but also perceptive, mimetic, gestural, and cognitive” (1987: 7).

Strangely, Eco does not consider this point in his comment on the rhizomatic model. However, the property is implicit in the encyclopedia model, all the "very diverse acts" listed by Deleuze and Guattari are not different in a

21 We can make an interesting comparison with Roman Jakobson, when he says that a sign can be interpreted following two dimensions: the code and the context (See Jakobson 1963). It is possible to trace the path from Peircean interpretation to the encyclopedic semiotic net, which is multidimensional. 
general sense, because they are all signs. Every step of the interpretive process, regardless of its particular kind as a sign, is a "semiotic chain," a link in the continuous chain of semiosis.

The principle of heterogeneity finds its sense in being clearly placed against the purely mentalistic or formal approaches that try to restrict the process of interpretation to linguistic thought or "abstract signs." It is important to maintain that interpretation and semiosis in general are highly complex processes, taking place in a continuum which cannot be restricted to "mind" and individual body and behavior. No valid theory of interpretation can be confined to the semantics of natural language, such theories are only formal reductions of an inquiry that can start and end solely in the pragmatic sphere.

\subsection{Localism}

Deleuze and Guattari state the third principle in this way: "There are no points or positions in a rhizome, such as those found in a structure, tree or root. There are only lines" (1987: 8).

Eco notes, "this feature is doubtful: intersecting lines make points" (1984a: 81). Deleuze and Guattari probably meant that in the rhizome there are no positions with respect to absolute coordinates. Every such system can only be relative. The knowledge one can have of the encyclopedia is only local: "No one can provide a global description of the whole rhizome" specifies Eco, and adds, "A structure that cannot be described globally can only be described as the potential sum of local descriptions” (1984a: 82).

This characteristic, that we may call localism, can be derived (and vice versa) from the principle of cartography (see Section 6.6). Since there is neither a generative rule nor a structure, it is impossible to have a theoretical knowledge of the encyclopedia. The only possible knowledge is pragmatic, the actual exploration by performance of interpretive paths. Now we understand why Eco talks about a labyrinth. A labyrinthine structure, in which explorers without any general map or rule to orientate themselves, can explain localism and pragmatic interpretation.

Eco explains that

in a structure without an outside, the describer can look at it only from the inside; as Rosenstiehl $(1971,1980)$ suggests, a labyrinth of this kind is a myopic algorithm; at every node of it no one can have the global vision of all its possibilities but only the local vision of the closest ones: every local description of the net is an hypothesis, subject to falsification, about its further course; in a rhizome, blindness is the only way of seeing (locally), and thinking means to grope one's way. (Eco 1984a: 82) 
In this omnicomprehensive environment structured knowledge appears as a subset:

Such a notion of encyclopedia does not deny the existence of structured knowledge; it only suggests that such a knowledge cannot be recognized and organized as a global system; it provides only "local" and transitory systems of knowledge, which can be contradicted by alternative and equally "local" cultural organizations; every attempt to recognize these local organizations as unique and "global" - ignoring their partiality - produces an ideological bias. (Eco 1984a: 84)

\subsection{Observers and explorers}

The principle of localism has consequences that go beyond the description of models and imply epistemological positions. Both Eco and Deleuze and Guattari stress the point that the labyrinthine model is a myopic algorithm. Rosenstiehl calls myopic algorithms the rules that an explorer adopts to solve a labyrinth from the inside. The labyrinth, in fact, can be dealt with in two ways, whether the solver is outside the labyrinth or inside it.

If the solver is outside (such as Daedalus while drawing the project of his building) he has a view from above, and works out a solution looking at the general traits of that particular labyrinth (for instance, whether there are cycles, the number of dimensions which it occupies, the number of exits, the typology of the labyrinth). ${ }^{22}$

If the solver is inside (such as Daedalus is after having been imprisoned in his own building), the rules he must follow to find his way are necessarily myopic rules, since his sight is limited to the corridor he is walking in, and to the corridors that open to a crossroad. The explorer can only mark the path he has walked, thus avoiding going the same way twice, but he lacks any other help. So, all the knowledge that can be gathered about the environment comes from Ariadne's immediate surroundings, her memory (the ability of marking the path which is Ariadne's thread) and her reasoning powers. The theory of labyrinths provides a myopic solution to finding the way in any kind of structure (even if there is time enough for the explorer to try the whole course of the labyrinth, in the worst-case scenario). ${ }^{23}$

22 There are, according to modern labrinthology, three kinds of labyrinths (see Eco 1984a: 80; Rosenstiehl 1979). The third type corresponds to the encyclopedic model.

23 Labyrinths can be solved following Tarry's Rule. If we consider a labyrinth as a context-free grammar, we obtain two rules, which Rosenstiehl calls the Rule of Ariadne-the-Fool and the Rule of Ariadne-the-Wise, depending on the more or less courageous strategy of the solver (see Rosenstiehl 1979: 21, 24-25). 
Even if the explorer knows only what he can see from the position he occupies, yet he is able, step by step, not only to get out of the labyrinth but even to draw a map of it. This map will be different from that of an external observer, but it is equally suitable for moving with success within the labyrinth and, furthermore, the diagram drawn by the inner explorer is, from every point of view, a valid description of the environment. Of course, the explorer must work out his model by means of hypotheses and successive approximations, and it takes some time to draw the main lines of the description. On the other hand, the external observer can see everything at a glance; thus, he can draw a model by means of a trait-to-trait transposition. Then, he will move a symbol on the model, as if it were the explorer (such are the labyrinths that are solved by children on the page of a book). In this way, the process is analogous to the construction of a myopic algorithm, though faster, owing to the small size of the model. However, even an external observer, if he wants to find the formula of the labyrinth, must follow the same method as the voyager. The "internal" procedure is clearly more complex, and requires reasoning and inference, whereas from outside we must produce just a simple calque of the original (see Section 6.6), but in labyrinths and encyclopedias there is no choice of perspective: the only logical solution is from the inside. This assumption makes every encyclopedia a local description. For this reason I called the third principle "localism."

The first two principles have been expressed with regard to the objective characters of the encyclopedia. But localism is not the objective trait of a structure. We cannot say that something is local in itself. Localism is a kind of relation between the knowing subject and the environment, marked by the impossibility to have a global vision. It is a trait of knowledge, not of the "known"; it is a relation, not a predicate. Thus, there is a difference between the first two principles and the third one. There is also a certain contradiction. Heterogeneity and connectibility are qualities that only an external observer can evince with certainty.

In fact, an internal explorer may fail to notice different kinds of signs if his memory is short and if he is going through a large homogeneous area of the labyrinth (it has been stated by some explorers, for instance, that the labyrinth is made only of concepts). Nonetheless, if the exploration is long enough (compared to the labyrinth's size) and if the explorer is able to memorize all his steps, he will probably be able to decide whether or not the structure possesses heterogeneity and/or connectibility. However, while to an external eye these questions are always decidable, we cannot say the same for the explorer: the above conditions must be fulfilled. 
The first two principles consider the encyclopedia as an objective structure capable of possessing or not possessing some properties. To be more precise, they don't talk about encyclopedia, but about a description of an encyclopedia, that is, a model of a model. The third principle explains how we obtain that model, its hypothetical nature, the relation between the object and the subject that constitute it. If we don't explain this change of perspective the whole discourse is obscure.

\subsection{Tolerance of contradictions}

The fourth property of Deleuze and Guattari's rhizome is called "A rhizome may be broken, shattered at a given spot, but it will start up again on one of its old lines, or on new line" (1987: 9).

Eco comments that the notion of a rhizome that can be broken and reconnected seems quite an obscure statement (1984a: 81). If it means that any connection between two portions of knowledge can be broken, and any of them can be re-connected to other portions of knowledge, this is a consequence of the first principle, seen in a dynamic way. Since, as we have seen above, the representation is local and it cannot represent in one point all the contents of the encyclopedia, then we must specify which of the two perspectives we will adopt, the external or the internal.

In the pseudo-objective encyclopedia every point is connected to every other, and no connection can be cut. The pseudo-objective encyclopedia is like the Library of Babylon, it contains everything that has been conceived by man and every point can be reached from any other. On the other hand, links can be made and cancelled if we come to partial encyclopedias. In the Middle Ages, for instance, no link of inclusion was established between the whale and the class of mammals. Whales were fish. In the contemporary encyclopedia the link is present, but, for example, not for babies that don't yet know the difference between a fish and a mammal. From the internal perspective there can be dynamic ruptures and re-connections, because the labyrinth is continuously changing. The myopic algorithm, in fact, should also take into account diachronic changes.

But the most important trait of the fourth principle, the derivation of which is not completely clear in Deleuze and Guattari, is what we may call the "tolerance of contradiction." "There is a rupture in the rhizome whenever segmentary lines explode into a line of flight, but the line of flight is part of the rhizome. These lines always tie back to one another. That is why one can never posit a dualism or a dichotomy, even in the rudimentary form of the good and the bad." (1987: 9). 
In Eco's words

in a structure in which every node can be connected with every other node, there is also the possibility of contradictory inference: if $p$, then any possible consequence of $p$ is possible, including the one that, instead of leading to new consequences, leads again to $p$, so that it is true at the same time both that if $p$, then $q$ and that if $p$, then non $q$. (Eco 1984a: 82)

As we see, Eco correctly derives the tolerance of contradiction from the topological property of total connection of a set of points, or nodes in a net. Deleuze and Guattari stress the impossibility of dualism and dichotomy. This doesn't mean that it is impossible to build any non-contradictory structure, but only that no such logic can have an absolute value, all of them are only disposable tools for a temporary task.

Once again we see that the tolerance of contradiction is, when attributed to a net of interpretants, acceptable and harmless. The network has a dynamic character, that is, its multidimensional structure occupies space, time, and possibility, and of course the encyclopedia may or may not host contradictions within its synchronic borders, but it will surely contain some contradictions in its diachronic borders, as in the above example of the whale. The description of the line of fugue, then, fits with the image of the dynamic net of interpretants. In the dynamic model of encyclopedia, the analytical logic based on the principle of non-contradiction can go along with the tolerance of contradiction, the former as a sort of timeless section of a local area of the flowing stream of interpretation, the latter as the description of the stream in its flowing.

Eco, instead of openly attacking the value of dualism and categorization, prefers to stress the way in which this conclusion is attained, that is, by considering the multi-cultural capacity of the encyclopedia and the dialectic development of discourse. The former capacity is described in this way, "[The universe of semiosis] takes into account multiple interpretations realized by different cultures: a given expression can be interpreted as many times, and in as many ways, as it has been actually interpreted in a given cultural framework." The dialectic aspect of discourse is thus stressed, "[The universe of semiosis] does not register only 'truths,' but, rather, what has been said about the truth or what has been believed to be true as well as what has been believed to be false or imaginary or legendary, provided that a given culture had elaborated some discourse about some subject matter" (Eco 1984a: 83). 


\subsection{Chart versus calque}

The fifth and sixth principles of Deleuze and Guattari's rhizome are called "principle of cartography and decalcomania," and specifies the characteristics of the rhizome with respect to structural and generative models, "a rhizome is not amenable to any structural or generative model" (1987: 12). That is to say that the rhizome cannot be reduced either to a set of oppositions nor to a series of axiomatic rules capable of constructing it.

Deleuze and Guattari compare the rhizomatic model to a chart in opposition to a calque, "The map has to do with performance, whereas the tracing always involves an alleged "competence"” (1987: 13). The pragmatic trait is stressed once more. The main difference between chart and calque, in fact, seems to be that the latter is a model related to its object by some known rule or linear function, whereas the former is related to its object by some "rule in progress," or indeterminate function.

The characteristics of the chart are those of an elastic kind of representation. "The map is open and connectable in all of its dimensions; it is detachable, reversible, susceptible to constant modification" (1987: 12). Eco translated almost literarily when he states, "A rhizome is not a calque but an open chart which can be connected with something else in all of its dimensions; it is dismountable, reversible, and susceptible of continual modifications" (1984a: 81). However, all these properties are implicit in a net of interpretants, and consequently Eco does not transport the principle of cartography into his own model.

This principle is a consequence of the third point, localism. It is not always clear, on the other hand, whether Deleuze and Guattari speak of what the rhizome stands for or of what it is. The rhizome is only a model whose referent is the process of interpretation. Maybe we can say that the fifth principle talks about the model of the model, and it regards the problems treated above (point number three). If the rhizome is the general form of the labyrinth, its local representations must be charts, and not calques. The chart is the local model, the ground upon which to formulate the pseudo-objective hypothesis of the rhizome.

\subsection{Dictionary as a sub-system}

With regard to the principle of decalcomania, its function is to explain how, inside a rhizome or an encyclopedia, we can find rigid models such as trees, dictionaries or other standard-coded structures. Such structures are subsets or clippings cut out of the general encyclopedic representation, and made coherent by non-contradictory logic. In turn, trees and other easy-to-handle structures 
can open themselves and produce an encyclopedic model. Deleuze and Guattari describe this property, following the rhizomatic metaphor, "There exist tree or root structures in rhizomes; conversely, a tree branch or root division may begin to burgeon into a rhizome” (1987: 15). In Eco’s words, “A network of trees which open in every direction can create a rhizome (which seems to us equivalent to saying that a network of partial trees can be cut out artificially in every rhizome)" (1984a: 81).

After having presented and commented on the encyclopedia, Eco can now come back to the dictionary, considered now "as a tool" (1984a: 84), that is, a local description, reversing the initial position, "one should turn upside down a current distinction between dictionary (strictly 'semantic') and encyclopedia (polluted with 'pragmatic' elements); on the contrary, the encyclopedia is a semantic concept and the dictionary is a pragmatic device" (1984a: 85). However, as I said above, the encyclopedia is not only an elegant solution to the problem of representing semiosis, it is the only explicative model that can account for many semiotic, linguistic and cultural phenomena that the globalized world daily puts presents us with.

\section{1990: "Please stop the interpretation: I want to step out!"}

In the 1980s the approach to text analysis called deconstruction, and its inventor, Jacques Derrida, were very popular, particularly in American universities. Peirce's unlimited semiosis was often cited as similar to deconstruction, which is a very free way of talking about texts, denying any criteria to validate interpretation.

Eco thus dedicated a book, published in 1990, to exploring the rules of good interpretation. ${ }^{24}$ In it he completes his semiotics by adding to the theory of sign production of $A$ Theory of Semiotics (how man produces signs), to the theory of text in Lector in fabula and The Role of the Reader (how signs have meaning), and some elements of a theory of reception (how man understands signs) in The Limits of Interpretation.

With regard to the limitative principles mentioned above, Eco's position is the same as before, but the criterion of internal coherence of the text assumes a more important role (1990: 33). This criterion is a testing ground for the universe

24 The Limits of Interpretation and I limiti dell'interpretazione were both published in 1990. They contain some parts that are translations (with some adaptations for cultural reasons), and some parts that appear only in one or the other of the two versions. 
of discourse activated by the interpreter, and is framed in the hypotheticalexperimental process supported by abduction (see Peirce $C P$ 7.164-255). The element of novelty is, however, the adoption of the Peircean idea of community as the depositary and builder of the image of reality, "The thoughts or opinions that define reality must therefore be linked to a community of experts, and this community must be structured and governed in a manner that takes into account supra-individual principles" (1990: 335, my translation; see Peirce CP $5.264-317,5.358-387,5.388-410) .{ }^{25}$ The instrument of this educational activity is interpretation:

From the moment a community agrees on a given interpretation, it creates a meaning that, if not objective, is at least intersubjective, and it is anyway privileged with respect to any other interpretation obtained without the community's agreement. The result of the process of universal research moves in the direction of a core of common ideas. (Eco 1990: 336, my translation) $)^{26}$

The question of the limits of interpretation in Eco is thus resolved by five criteria:

a) pragmatic: the interpretations are based on habit-making;

b) universe of discourse: every interpretation must be placed in a universe of discourse which is part of a theoretically unlimited Semantic Universe (Encyclopedia);

c) implicit competence: every text must be interpreted by means of the competence that actualizes it in the most coherent way with respect to the conditions of its production;

d) internal coherence: an interpretive hypothesis that renders coherent a part of the text must also work on the entire text;

e) communitary: the tendency of a community of interpreters of a text to agree on common hypotheses.

25 Original text from I limiti dell'interpretazione: "Il pensiero o l'opinione che definisce la realtà deve dunque appartenere a una comunità di esperti, e questa comunità deve essere strutturata e disciplinata tenendo conto di principi sovra-individuali” (1990: 335)

26 Original text from I limiti dell'interpretazione:

dal momento in cui la comunità è indotta a concordare su una data interpretazione si crea un significato che, se non oggettivo, è almeno intersoggettivo ed è comunque privilegiato rispetto a qualsiasi altra interpretazione ottenuta senza il consenso della comunità. Il risultato del processo di ricerca universale va nella direzione di un nucleo di idee comuni. (Eco 1990: 336) 
Taken together, these criteria constitute the starting point for the foundation of a pragmatics of textual inquiry (taking text in its wider sense) built by extending the theory of interpretation of Charles S. Peirce.

\section{Conclusion}

Umberto Eco took the basic concepts of his semiotics from Charles S. Peirce, and after three decades, also adopted Peirce's founding approach. Peirce, as the study of his papers and manuscripts continues to develop, appears more incontrovertibly as an outstanding figure in Western thought. Thus, Eco's adoption is the acknowledgment of an inquiry of rare determination and depth. Yet, the accuracy of Eco's analysis, and the way he expands Peirce's theory and throws light into its darkest corners, renders his work an original continuation of the path opened by the American philosopher. At the same time, Eco grafts onto the tree of interpretive theory the most suitable tools of the European structuralist tradition and the Italian aesthetic school. And, last but not least, he dresses even the most arid topic with his personal wit.

\section{References}

Bonfantini, Massimo A. 1980. Introduzione: La semiotica cognitiva di Peirce. In C. S. Peirce (ed.), Semiotica, xxi-lii. Torino: Einaudi.

Bonfantini, Massimo A. 1987. La semiosi e l'abduzione. Milan: Bompiani.

Deleuze, Gilles \& Felix Guattari. 1972. L'Anti-CEdipe. Paris: Les Editions de Minuit.

Deleuze, Gilles \& Felix Guattari. 1976. Rhizome. Paris: Les Edition de Minuit.

Deleuze, Gilles \& Felix Guattari. 1987. A thousand plateaus. Minneapolis, MN: University of Minnesota Press.

Eco, Umberto. See Selected Bibliography in this volume.

Eco, Umberto and Sebeok, Thomas A. 1984. The Sign of Three: Dupin, Holmes, Peirce. Bloomington, IN: History Workshop, Indiana University Press.

Jakobson, Roman. 1963. Essais de linguistique générale. Paris: Les Edition de Minuit. Lotman Jurij. 1990. Universe of mind: A semiotic theory of culture. London \& New York: I.B. Tauris.

Peirce, Charles S. 1931-1966. The collected papers of Charles S. Peirce, 8 vols., C. Hartshorne, P. Weiss \& A. W. Burks (eds.). Cambridge: Harvard University Press. [Reference to Peirce's papers will be designated $C P$ followed by volume and paragraph number.]

Petitot, Jean. 1977. Centrato/acentrato. In Enciclopedia Einaudi, vol. 2, 894-954. Torino: Einaudi.

Proni, Giampaolo. 1981. Genesi e senso dell'abduzione in Peirce. Versus 28. 29-50.

Proni, Giampaolo. 1983. L'abduzione di Keplero. Versus 34. 37-58. 
Proni, Giampaolo. 1988. Umberto Eco: An intellectual biography. In Thomas A. Sebeok \& Jean Umiker-Sebeok (eds.), The semiotic web 1987, 3-22. Berlin: Mouton de Gruyter.

Proni, Giampaolo. 1990. Introduzione a Peirce. Milan: Bompiani.

Proni, Giampaolo. 1992. La terminologia scientifica e la precisione linguistica secondo C. S. Peirce. Versus 61/63. 247-259.

Proni, Giampaolo. 1998. The position of Eco. In Roland Posner, Klaus Robering \& Thomas A. Sebeok (eds.), Semiotik/semiotics: $A$ handbook on the sign-theoretic foundations of nature and culture, 2311-2320. Berlin \& New York: Walter de Gruyter.

Rosenstiehl, Pierre. 1971. Labyrinthologie mathématique (I). Mathématique et Sciences humaines 33. 5-32.

Rosenstiehl, Pierre. 1979. Labirinto. In Enciclopedia Einaudi, vol. 8, 3-30. Torino: Einaudi.

Rosenstiehl, Pierre. 1980. Les mots du labyrinthe. In Jean-Loup Rivière (ed.), Cartes et figures de la terre, 94-103. Paris: Centre Culturel Pompidou.

Rosenstiehl, Pierre \& Jean Petitot. 1974. Automate asocial et systèmes acentrés.

Communications 22. 45-62.

Violi, Patrizia. 1998. Individual and communal encyclopedias. In N. Bouchard \& V. Pravadelli (eds.), Umberto Eco's alternative: The politics of culture and the ambiguities of interpretation, 25-28. New York: Peter Lang. 